\title{
Combined Corrosion and Wear of Aluminium Alloy 7075-T6
}

\author{
Yueting Liu ${ }^{1}$ J. M. C. $\mathrm{Mol}^{2}$ - G. C. A. M. Janssen ${ }^{1}$
}

Received: 14 December 2015/Revised: 6 March 2016/Accepted: 22 March 2016/Published online: 5 April 2016

(C) The Author(s) 2016. This article is published with open access at Springerlink.com

\begin{abstract}
The aluminium alloy 7075-T6 is widely used in engineering. In some applications, like slurry transport, corrosion and abrasion occur simultaneously, resulting in early material failure. In the present work, we investigated the combined effect of corrosion and wear on the aluminium alloy 7075-T6. We performed two series of wear experiments to vary the conditions and severity of corrosion environment: chemically by using ethanol, deionized water and seawater, and electrochemically by applying various potentials using a potentiostat in seawater. Results show that, in seawater, the wear rate was higher than in deionized and ethanol; and in the potentiostat experiments, at the anodic potentials, the wear rates were higher than at the open circuit potential and the cathodic potentials. Seawater is the most corrosive one among the three liquids and the corrosion products can be easily removed. When applying anodic potentials, corrosion is accelerated, and the higher wear rate confirms that higher corrosion rate leads to higher wear rate due to the formation and removal of corrosion products during tribocorrosion.
\end{abstract}

Electronic supplementary material The online version of this article (doi:10.1007/s40735-016-0042-3) contains supplementary material, which is available to authorized users.

Yueting Liu

y.liu-4@tudelft.nl

1 Materials Innovation Institute M2i, Department of Precision and Microsystems Engineering, Delft University of Technology, Mekelweg 2, 2628CD Delft, The Netherlands

2 Department of Materials Science and Engineering, Delft University of Technology, Mekelweg 2, 2628CD Delft, The Netherlands
Keywords Aluminium alloy · Electrochemistry - Wear · Corrosion

\section{Introduction}

The aluminium alloy 7075-T6 (AA7075-T6) is used extensively in engineering [1-4]. This alloy has good mechanical properties, like high-specific strength comparable with high strength steel $[5,6]$. It offers the potential of significant reduction of weight, which is vital in some applications $[1$, 4]. However, the wider use of AA7075-T6 is limited by two main factors: the susceptibility to localized corrosion and the poor tribological properties due to its relatively low hardness and high tendency to adhesion $[7,8]$.

Many researchers have studied the localized corrosion of AA7075-T6 [7, 9-12]. The susceptibility, to localized corrosion, like pitting, intergranular or exfoliation corrosion, is related to the type, concentration and distribution of intermetallics and strengthening particles. They have different reactivities from the matrix, which could lead to galvanic coupling [13]. The intermetallics and strengthening particles have been characterized with techniques like scanning Kelvin probe force microscopy (SKPFM) or micro-capillary studies [14-17]. In AA7075-T6, $\mathrm{Al}_{7} \mathrm{Cu}_{2} \mathrm{Fe}$ and $(\mathrm{Al}, \mathrm{Cu})_{6}$ $(\mathrm{Fe}, \mathrm{Cu})$ are the main intermetallics, which are electrochemically less active than the matrix, and therefore they could lead to the dissolution of the surrounding areas [12]. The main strengthening particles contain $\mathrm{MgZn}_{2}$ and the size is in the range of nanometres. These particles precipitate, during heat treatment or ageing, along grain boundaries. They are electrochemically more active than the matrix, and thus, they may lead to the intergranular corrosion of AA7075-T6 [7].

In addition to the research of the corrosion properties, the tribological properties of AA7075-T6 have also been 
studied [8, 18]. In those studies, the effects of surface treatment like plasma electrolytic oxidation or ion implantations on the wear properties of AA7075-T6 have been reported. Sabatini et al. [8] reported that plasma electrolytic oxidation treated AA7075-T6 has an significant increase in wear resistance with respect to the base material. Cristobal et al. [18] concluded that the dominant wear mechanism of AA7075-T6 is adhesive-abrasive and this mechanism is not modified by the implantation process.

However, in some applications, like slurry transport, aluminium alloys are subject to combined corrosion and abrasion, and the two processes may enhance each other, leading to early material failure. The mechanism of combined corrosion and wear, also known as tribocorrosion, is complex, involving mechanical, chemical and electrochemical factors [19, 20]. For AA7075-T6, the mechanism of combined corrosion and abrasion is rarely understood and this work studies it in detail.

This work studies the wear mechanism of combined corrosion and abrasion of aluminium alloy 7075-T6. A modified pin-on disc tribometer, connected with a potentiostat, is used in order to impose intended corrosion conditions. Open circuit potential (OCP), anodic and cathodic potentials are applied. Wear experiments are performed under combined mechanical and (electro)chemical conditions, by means of electrochemical techniques and friction control.

\section{Experimental}

\subsection{Material Preparation}

The material, AA7075-T6, was cut to cylinders with $30 \mathrm{~mm}$ diameter and $8 \mathrm{~mm}$ thickness, to fit the holder of the pin-on-disc tribometer. The main compositions of the

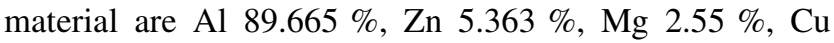
$1.719 \%$, Cr $0.244 \%$, Fe $0.184 \%$, Si $0.115 \%$. After cutting, all the samples were sanded and polished using silicon carbide sandpaper (up to 2400-mesh) and diamond-containing polishing liquid (down to $1 \mu \mathrm{m}$ ), respectively, until the finish was mirror-like. Before the experiments, samples were cleaned in an ultrasonic bath in acetone to degrease, followed by rinsing and drying. During experiments, an alumina ball, with $6 \mathrm{~mm}$ diameter, was used as the counterpart. After each experiment, the ball was either rotated or replaced to assure fresh and similar contact in the beginning of each experiment.

\subsection{Tribocorrosion Experiments}

Tribocorrosion experiments, performed with pin-on-disc tribometry, consisted of two series with different methods to vary the corrosive conditions: chemically using different liquids and electrochemically using a potentiostat in $3.5 \%$ $\mathrm{NaCl}$ solution. For both conditions, the load was $8 \mathrm{~N}$ and the radius was $5 \mathrm{~mm}$. In the chemical setup, rotational speed was varied from 0.25 to $2.5 \mathrm{~Hz}$ (corresponding to $15-150 \mathrm{rpm}$ ) and time was varied from 1 to $25 \mathrm{~min}$. Three liquids were used: ethanol, deionized water and $3.5 \%$ $\mathrm{NaCl}$ solution (mimicking the typical chlorine concentration of seawater, and henceforward referred to as seawater) to provide non-corrosive, slightly corrosive and strongly corrosive environments, respectively. In the electrochemical setup, a three-electrode cell configuration potentiostat (Autolab) was connected with the pin-on-disc tribometer. In the three-electrode system, the sample acted as the working electrode, and the counter and reference electrodes were graphite and $\mathrm{Ag} / \mathrm{AgCl}$, respectively. Additionally, the pin and the sample holder, both originally made of aluminium, were replaced by plastic ones to avoid possible electrical leakage and stray currents. All the electrochemical experiments were performed in seawater. Before applying a certain potential, the open circuit potential (OCP) was measured. Relative to OCP, potentials in both cathodic and anodic domains were applied. Specifically, -0.5 and $-1.0 \mathrm{~V}$, relative to OCP, were applied to shift the potential cathodically versus OCP, in order to suppress corrosion. On the other hand, 0.2 and $0.5 \mathrm{~V}$, relative to OCP, were chosen to shift the potential anodically versus $\mathrm{OCP}$, in order to accelerate the corrosion. Before the start of sliding, each sample was immersed in seawater at the applied potential for $180 \mathrm{~s}$, and thereafter the pin was put in the liquid for another $120 \mathrm{~s}$, followed by 300 laps (10 min) of sliding with $30 \mathrm{rpm}$ in speed. After the end of sliding, the pin stayed in contact with the sample for $120 \mathrm{~s}$ before lifted. The total time of each electrochemical experiment was $18 \mathrm{~min}$ (1080 s). Each test was repeated three times to assure reproducibility. The mean value and standard deviation was calculated and reported to compare groups of data.

\subsection{Characterization}

After the tribocorrosion experiments, the wear track profiles were measured by white light interferometry. The wear rate was calculated by multiplying the area of cross section by the perimeter of the wear track, and then divided by sliding distance [21]. Additionally, Scanning Electron Microscopy (SEM) was used to observe and analyze corrosion morphologies. Multiple locations of the worn and unworn areas were observed by SEM from various magnifications to assure the representativeness. Energy Dispersive X-Ray Spectroscopy (EDS) was used to analyze the chemical composition of particles and corrosion products at the worn and unworn areas. 


\section{Results}

\subsection{Wear Response in Different Corrosive Environments}

The sample wears the most in seawater, the least in ethanol and the intermediate in deionized water, regardless of rotational speed (Fig. 1a) or time duration (Fig. 1b). In seawater and ethanol, wear rate remains stable regardless of speed or time duration. For deionized water, at lower rotational speed $(0.25$ and $0.5 \mathrm{~Hz})$, i.e. longer time intervals, the wear rate is larger than that at higher rotational speed. Figure 2 shows the relationship between wear rate and electrochemical potentials in seawater. The OCP was measured as $-0.68 \mathrm{~V}$ relative to $\mathrm{Ag} / \mathrm{AgCl}$ reference electrode. In the anodic domain, as shown in Fig. 2, the sample wears much more than in the cathodic domain, as well as at OCP. Additionally, when applying a higher potential, in the anodic domain, wear rate increases. At $\mathrm{OCP},-0.68 \mathrm{~V}$, wear rate is roughly $0.026 \mathrm{~mm}^{3} / \mathrm{m}$; when increasing the potential by 0.2 to $-0.48 \mathrm{~V}$, wear rate increases sharply to $0.053 \mathrm{~mm}^{3} / \mathrm{m}$, twice the rate at OCP; when applying an even higher potential at $-0.18 \mathrm{~V}(0.5 \mathrm{~V}$ relative to $\mathrm{OCP})$ wear rate increases to $0.067 \mathrm{~mm}^{3} / \mathrm{m}$. In the cathodic domain, both at $-1.68 \mathrm{~V}$ $(-1.0 \mathrm{~V}$ vs $\mathrm{OCP})$ or $-1.18 \mathrm{~V}(-0.5 \mathrm{~V}$ vs $\mathrm{OCP})$, wear is comparable with the wear at OCP.

\subsection{Surface Morphology After Experiments at Various Potentials}

The morphology of the unworn area of the samples subjected to various potentials was observed by SEM as shown

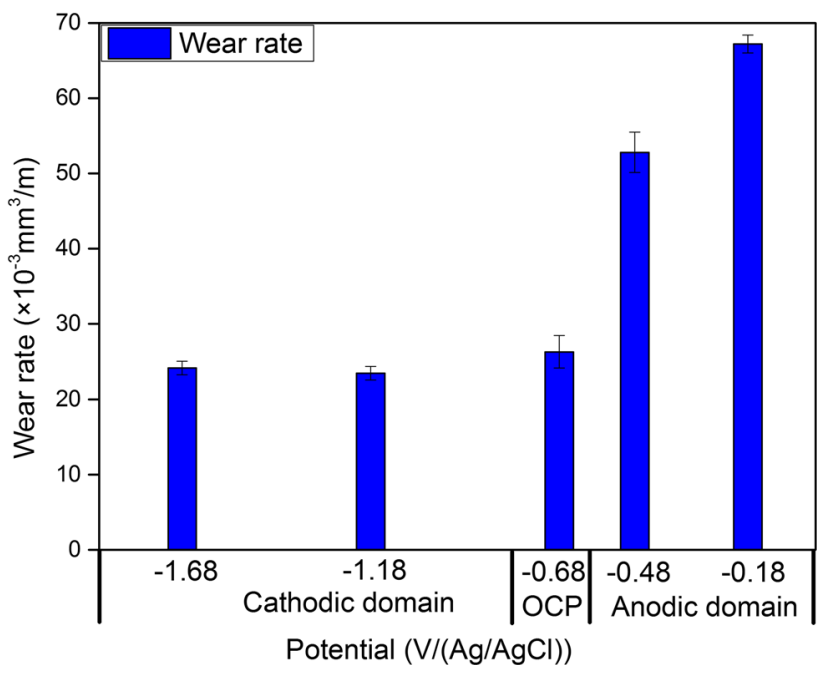

Fig. 2 Wear rate at various potentials. All potentials were relative to $\mathrm{Ag} / \mathrm{AgCl}$ standard electrode

in Fig. 3. Grain boundaries are clearly visible as can be seen in Fig. 3a, indicating the occurrence of intergranular corrosion at $-1.68 \mathrm{~V}(-1.0 \mathrm{~V}$ vs $\mathrm{OCP})$. Figure $3 \mathrm{~b}$ shows local trenching, suggesting the occurrence of pitting corrosion, at $-1.18 \mathrm{~V}(-0.5 \mathrm{~V}$ vs $\mathrm{OCP})$. At the OCP (Fig. 3c), localized trenching and corrosion products were visible. In the anodic domain, the unworn area of the samples showed more corrosion products, as can be seen Fig. 3d, e, representing the occurrence of uniform corrosion at $-0.48 \mathrm{~V}(0.2 \mathrm{~V}$ vs OCP $)$ and $-0.18 \mathrm{~V}(0.5 \mathrm{~V}$ vs OCP). EDS analysis showed that the corrosion products contain $\mathrm{Al}, \mathrm{Mg}, \mathrm{Zn}$ and a large amount of $\mathrm{O}$. The worn area morphology of the samples subjected to various potentials
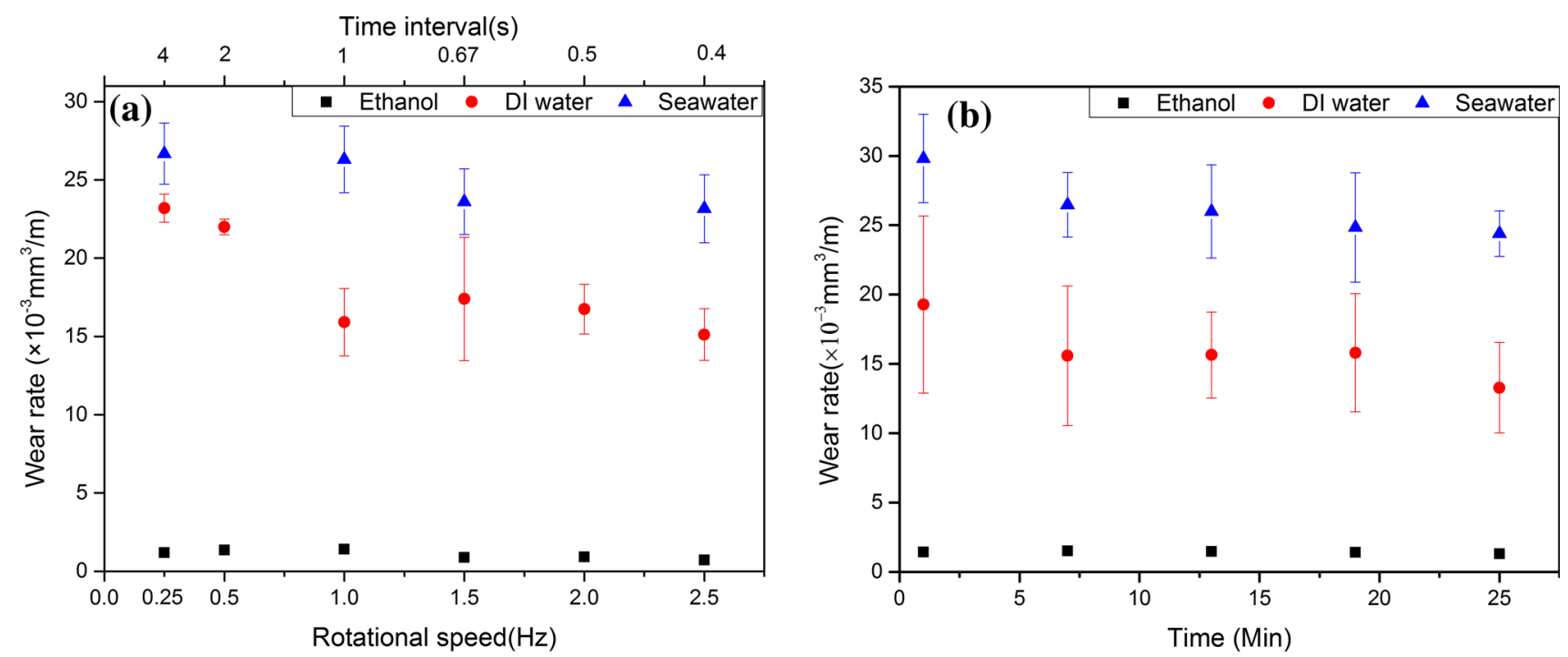

Fig. 1 a Wear rate as a function of rotational speed. The distance was 300 laps for each rotational speed, b wear rate as a function of time duration. The rotational speed was $1 \mathrm{~Hz}$. The load and radius were $8 \mathrm{~N}$ and $5 \mathrm{~mm}$ for all experiments, respectively 

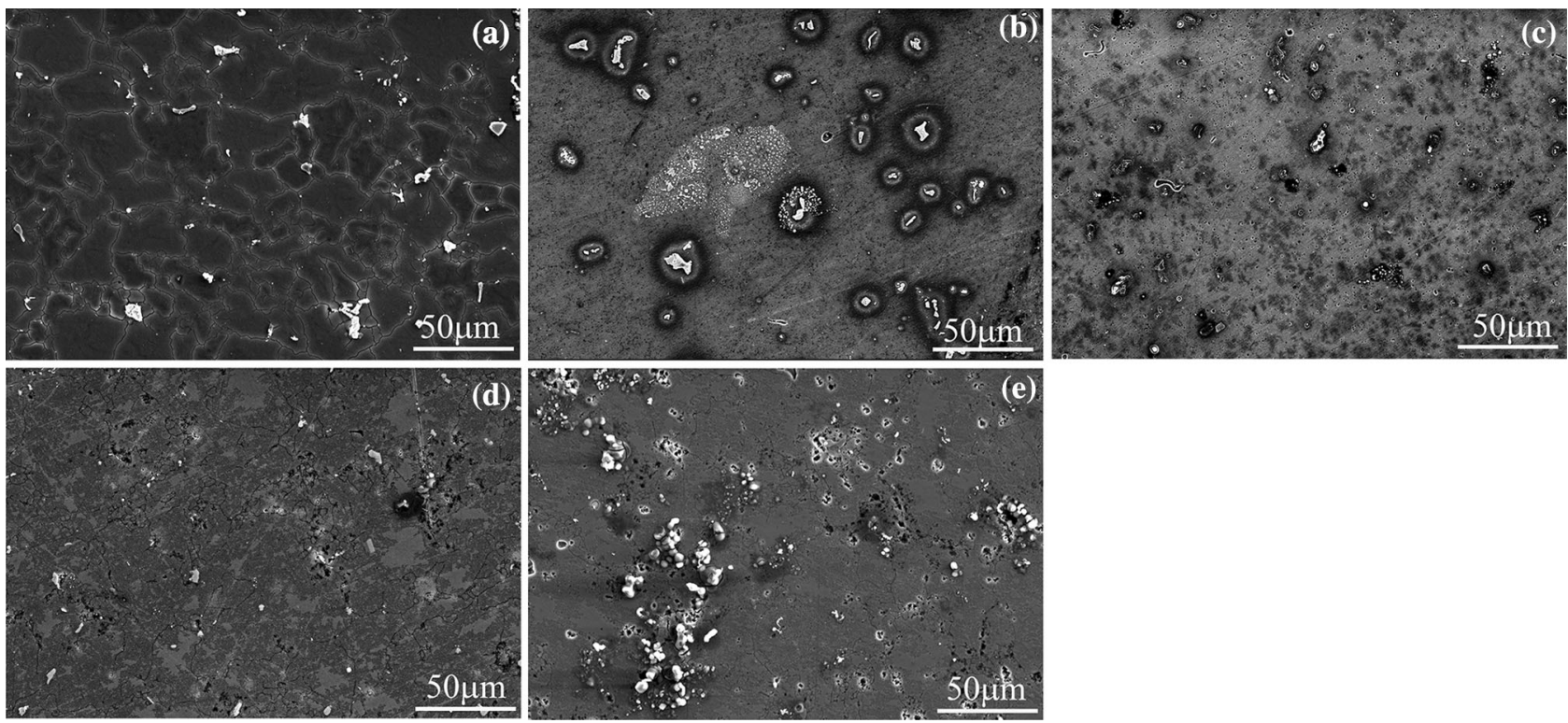

Fig. 3 Surface morphology of unworn areas after tribocorrosion at different potentials. a at $-1.68 \mathrm{~V}$, b at $-1.18 \mathrm{~V}$, $\mathbf{c}$ at $-0.68 \mathrm{~V}$, i.e. $\mathrm{OCP} ; \mathbf{d}$ at $-0.48 \mathrm{~V}$, e at $-0.18 \mathrm{~V}$. All potentials were relative to $\mathrm{Ag} /$ $\mathrm{AgCl}$ standard electrode. Since the OCP was $-0.68 \mathrm{~V}$, the five

is shown in Fig. 4. When subjected to the cathodic potential regime, as shown in Fig. $4 a$, b, the wear mechanism is mainly plastic deformation. Specifically, at $-1.68 \mathrm{~V}(-1 \mathrm{~V}$ vs $\mathrm{OCP})$, ploughed grooves are clearly visible, as shown in Fig. $4 \mathrm{a}$; at $-1.18 \mathrm{~V}(-0.5 \mathrm{~V}$ vs OCP), as shown in Fig. 4b, wedges appear in addition to grooves. At the OCP (Fig. 4c), both grooves and wedges are visible in the worn area, as well as few corrosion products. In the anodic domain, specifically at $-0.48 \mathrm{~V}(0.2 \mathrm{~V}$ vs OCP $)$ and $-0.18 \mathrm{~V}(0.5 \mathrm{~V}$ vs OCP $)$, the wear mechanism changed drastically. As can be seen in Fig. 4d, e, less grooves appeared, but more corrosion products were visible. The chemical composition of the products at the worn area was similar to that at the unworn area. (Detailed EDS results can be found in supplementary materials).

\subsection{Current Evolution at Various Potentials}

The current evolution with time at various potentials shows the influence of imposed potential on the current, subsequently corrosion (Fig. 5). In the cathodic domain, both at $-1.68 \mathrm{~V}(-1.0 \mathrm{~V}$ vs OCP) and $-1.18 \mathrm{~V}(-0.5 \mathrm{~V} \mathrm{OCP})$, the current was negative, indicating that no uniform corrosion on the whole surface occurred. Specifically, at $-1.68 \mathrm{~V}$, the current $(\sim-7.5 \mathrm{~mA})$ was more negative than the current at $-1.18 \mathrm{~V}$ (slightly below zero). In the anodic domain, the current at $-0.18 \mathrm{~V}(7.84 \pm 0.06 \mathrm{~mA})$ was, on average, $4.7 \%$ larger than the current at $-0.48 \mathrm{~V}$ $(7.49 \pm 0.01 \mathrm{~mA})$, indicating higher corrosion rate at potentials were $-1.0,-0.5,0.0,+0.2$ and $+0.5 \mathrm{~V}$ relative to the $\mathrm{OCP}$, respectively. The secondary electron imaging was conducted at acceleration voltage $10 \mathrm{kV}$ and the distance was $10 \mathrm{~mm}$

higher potential in the anodic potentials regime. For both anodic potentials, the positive corrosion current should lead to corrosion products on the surfaces of samples, as indeed observed on both unworn areas and worn areas, as shown in Figs. 3d, e and 4d, e, respectively.

\section{Discussion}

AA7075-T6 exhibits various types of corrosion like uniform corrosion, intergranular corrosion, pitting corrosion. in different corrosive environments $[11,22,23]$. The samples show much higher wear rate in corrosive liquid (seawater) than in non-corrosive liquid (ethanol) (Fig. 1), suggesting that corrosion generally increases wear rate. In deionized water, the wear rate was higher at the low rotational speed $(0.25$ and $0.5 \mathrm{~Hz})$ than at the higher rotational speed. At lower speed, the sample has a longer time interval to corrode, and more corrosion products can be removed by subsequent sliding, a process involving repassivation and depassivation [24]. This explains the higher wear rate $\left(\mathrm{mm}^{3} / \mathrm{m}\right)$ at lower speed in deionized water. At different rotational speeds in seawater, no noticeable difference can be observed, as shown in Fig. 1. This might be because the corrosion rate of AA7075-T6 in seawater is too fast for rotational speeds in the range of $0.25-2.5 \mathrm{~Hz}$ to make a difference [3].

Corrosion rate $\left(\mathrm{mm}^{3} / \mathrm{s}\right)$ is generally determined by the current of the sample according to Faraday's law [25, 26]. 

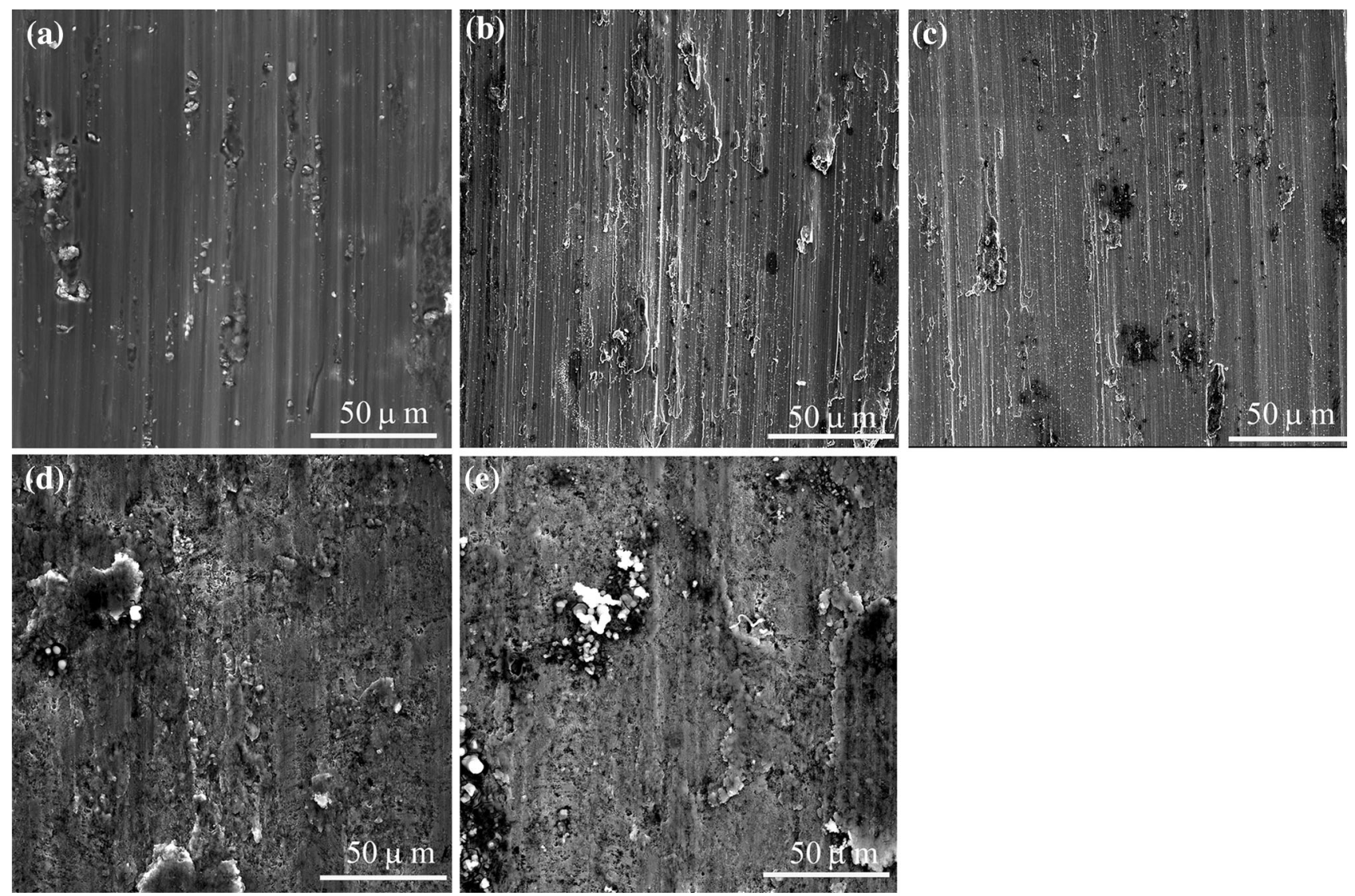

Fig. 4 Surfaces morphology of worn areas of samples subjected to different potentials. a at $-1.68 \mathrm{~V}, \mathbf{b}$ at $-1.18 \mathrm{~V}$, c at $-0.68 \mathrm{~V}$, i.e. $\mathrm{OCP} ; \mathbf{d}$ at $-0.48 \mathrm{~V}$, e at $-0.18 \mathrm{~V}$. All potentials were relative to $\mathrm{Ag} /$ $\mathrm{AgCl}$ standard electrode. Since the OCP was $-0.68 \mathrm{~V}$, the five

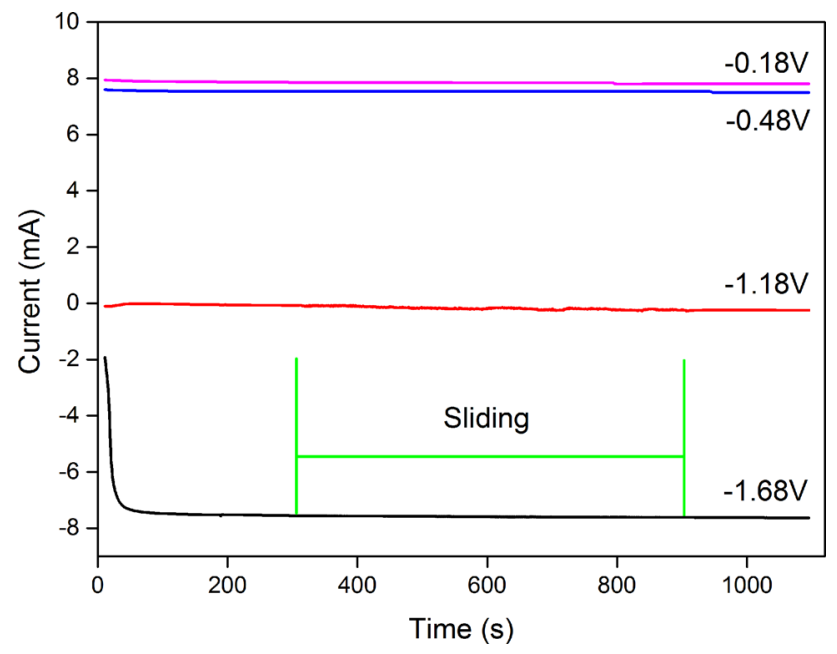

Fig. 5 The current evolution of the samples as a function of time at various potentials; All potentials were relative to $\mathrm{Ag} / \mathrm{AgCl}$ standard electrode. Since the OCP was $-0.68 \mathrm{~V}$, four potentials were -1.0 , $-0.5,+0.2$ and $+0.5 \mathrm{~V}$ relative to the OCP, respectively. The start $(300 \mathrm{~s})$ and end $(900 \mathrm{~s})$ of sliding are indicated potentials were $-1.0,-0.5,0.0,+0.2$ and $+0.5 \mathrm{~V}$ relative to the OCP, respectively. The secondary electron imaging was conducted at acceleration voltage $10 \mathrm{kV}$ and the distance was $10 \mathrm{~mm}$

In this study, the current at $-0.18 \mathrm{~V}(7.84 \pm 0.06 \mathrm{~mA})$ was, on average, $4.7 \%$ larger than the current at $-0.48 \mathrm{~V}$ $(7.49 \pm 0.01 \mathrm{~mA})$ (Fig. 5), indicating that the corrosion rate at $-0.18 \mathrm{~V}$ is higher than that at $-0.48 \mathrm{~V}$ by the application of a higher anodic overpotential. The higher corrosion rate corresponds to the higher wear rate, and this is in agreement with the result that the wear rate in seawater is higher than that in ethanol and deionized water, since seawater is the most corrosive one among the three liquids.

When applying a potential in the cathodic domain, corrosion is, in general, suppressed [27, 28]. However, in AA7075-T6, only uniform corrosion can be suppressed, relatively mild localized corrosion still occurs. After the experiment at $-1.18 \mathrm{~V}(-0.5 \mathrm{~V}$ vs OCP $)$, trenching was visible on the surface of the sample (Fig. 3b). The formation of trenching is generally determined by the presence of intermetallics. These intermetallics have different electrochemical potentials relative to the matrix according to the work of Birbilis et al. [12, 29], who summarized the 
electrochemical nature of the intermetallics family of AA7075-T6. The intermetallics and their surrounding areas may form micro-galvanic cells, leading to the formation of trenching [9, 10], as observed and shown in Fig. 3b. The occurrence of trenching implies the existence of localized corrosion, and the wear rate at $-1.18 \mathrm{~V}$ is still comparable with the wear rate at the OCP (Fig. 2), suggesting that localized corrosion is the reason that the wear rate at $-1.18 \mathrm{~V}$ (in the cathodic domain) does not drop noticeably. At $-1.68 \mathrm{~V}$, mild intergranular corrosion appeared along grain boundaries as shown in Fig. 3a. In AA7075-T6, the main precipitations of the strengthening particles contain $\mathrm{MgZn}_{2}$ [7]. These precipitations can create an anodic path for the localized attack along grain boundaries due to their extremely low electrochemical potential [29], leading to the intergranular corrosion [7, 9]. In this study, intergranular corrosion occurred at $-1.68 \mathrm{~V}(-1.0 \mathrm{~V}$ vs OCP), and the wear rate was still comparable with the wear rate at the OCP (Fig. 2), suggesting that intergranular corrosion is the reason that the wear rate at $-1.68 \mathrm{~V}$ (in the cathodic domain) does not drop noticeably. In the anodic domain, as shown in Fig. 3d, e, intergranular corrosion, local attack and uniform corrosion were all visible. Besides, in the anodic domain, more generation of gas than at the OCP was observed, indicating the higher intensity of corrosion reaction.

\section{Conclusions}

We studied the combined corrosion and wear of AA7075T6. Wear rate was much higher in seawater than in deionized water and ethanol, because of the high corrosion rate in seawater and the easy removal of corrosion products by subsequent sliding movement. When applying anodic potentials to accelerate corrosion rate, the wear rate became higher than that at OCP, further confirming that the higher corrosion rate leads to the higher wear rate of AA7075-T6 due to the formation and removal of corrosion films during tribocorrosion. When applying cathodic potentials on the sample in seawater, wear rate did not drop noticeably compared to the condition at the OCP. This is due to the occurrence of mild intergranular corrosion caused by strengthening precipitation particles, or localized corrosion caused by intermetallics.

Acknowledgments This research was carried out under Project Number M33.7.11427 in the framework of the Research Program of the Materials innovation institute M2i (www.m2i.nl).

Open Access This article is distributed under the terms of the Creative Commons Attribution 4.0 International License (http://crea tivecommons.org/licenses/by/4.0/), which permits unrestricted use, distribution, and reproduction in any medium, provided you give appropriate credit to the original author(s) and the source, provide a link to the Creative Commons license, and indicate if changes were made.

\section{References}

1. Miller W, Zhuang L, Bottema J et al (2000) Recent development in aluminium alloys for the automotive industry. Mater Sci Eng A 280:37-49. doi:10.1016/S0921-5093(99)00653-X

2. Deuis RL, Subramanian C, Yellupb JM (1997) Dry sliding wear of aluminium composites-a review. Compos Sci Technol 57:415-435. doi:10.1016/S0266-3538(96)00167-4

3. Vargel C (2004) Corrosion of aluminium. Elsevier Ltd, Oxford

4. Starke EA, Staley JT (1996) Application of modern aluminum alloys to aircraft. Prog Aerosp Sci 32:131-172. doi:10.1016/ 0376-0421(95)00004-6

5. Lee SW, Yeh JW, Liao YS (2004) Premium 7075 aluminium alloys produced by Reciprocating extrusion. Adv Eng Mater 6:936-943. doi:10.1002/adem.200400107

6. Liu D, Atkinson HV, Kapranos P et al (2003) Microstructural evolution and tensile mechanical properties of thixoformed high performance aluminium alloys. Mater Sci Eng A 361:213-224. doi:10.1016/S0921-5093(03)00528-8

7. Andreatta F, Terryn H, de Wit JH (2004) Corrosion behaviour of different tempers of AA7075 aluminium alloy. Electrochim Acta 49:2851-2862. doi:10.1016/j.electacta.2004.01.046

8. Sabatini G, Ceschini L, Martini C et al (2010) Improving sliding and abrasive wear behaviour of cast A356 and wrought AA7075 aluminium alloys by plasma electrolytic oxidation. Mater Des 31:816-828. doi:10.1016/j.matdes.2009.07.053

9. Andreatta F, Lohrengel MM, Terryn H, de Wit JHW (2003) Electrochemical characterisation of aluminium AA7075-T6 and solution heat treated AA7075 using a micro-capillary cell. Electrochim Acta 48:3239-3247. doi:10.1016/S00134686(03)00379-7

10. Birbilis N, Cavanaugh MK, Buchheit RG (2006) Electrochemical behavior and localized corrosion associated with $\mathrm{A} 17 \mathrm{Cu} 2 \mathrm{Fe}$ particles in aluminum alloy 7075-T651. Corros Sci 48:4202-4215. doi:10.1016/j.corsci.2006.02.007

11. Zupanc U, Grum J (2010) Effect of pitting corrosion on fatigue performance of shot-peened aluminium alloy 7075-T651. J Mater Process Technol 210:1197-1202. doi:10.1016/j.jmatprotec.2010. 03.004

12. Gao M, Feng CR, Wei RP (1998) An analytical electron microscopy study of constituent particles in commercial 7075-T6 and 2024-T3 alloys. Metall Mater Trans A Phys Metall Mater Sci 29:1145-1151. doi:10.1007/s11661-998-0240-9

13. Pao PS, Feng CR, Gill SJ (2000) Corrosion fatigue crack initiation in aluminum alloys 7075 and 7050. Corrosion 56:1022-1031. doi:10.5006/1.3294379

14. Böhni H, Suter T, Assi F (2000) Micro-electrochemical techniques for studies of localized processes on metal surfaces in the nanometer range. Surf Coat Technol 130:80-86. doi:10.1016/ S0257-8972(00)00681-2

15. Lohrengel MM, Moehring A, Pilaski M (2001) Capillary-based droplet cells: limits and new aspects. Electrochim Acta 47:137-141. doi:10.1016/S0013-4686(01)00570-9

16. Schmutz P (1998) Corrosion study of AA2024-T3 by scanning Kelvin probe force microscopy and in situ atomic force microscopy scratching. J Electrochem Soc 145:2295-2306. doi:10. $1149 / 1.1838634$ 
17. Schmutz P (1998) Characterization of AA2024-T3 by scanning Kelvin probe force microscopy. J Electrochem Soc 145:2285. doi:10.1149/1.1838633

18. Cristóbal MJ, Figueroa R, Mera L, Pena G (2012) Tribological behaviour of aluminium alloy AA7075 after ion implantation. Surf Coat Technol 209:124-130. doi:10.1016/j.surfcoat.2012.08. 050

19. Ponthiaux P, Wenger F, Drees D, Celis JP (2004) Electrochemical techniques for studying tribocorrosion processes. Wear 256:459-468. doi:10.1016/S0043-1648(03)00556-8

20. Landolt D (2006) Electrochemical and materials aspects of tribocorrosion systems. J Phys D Appl Phys 39:3121-3127. doi:10. 1088/0022-3727/39/15/S01

21. Rabinowicz E, Tanner RI (1966) Friction and wear of materials. J Appl Mech 33:479. doi:10.1115/1.3625110

22. Li JF, Peng ZW, Li CX et al (2008) Mechanical properties, corrosion behaviors and microstructures of 7075 aluminium alloy with various aging treatments. Trans Nonferr Metals Soc China (English Edition) 18:755-762. doi:10.1016/S1003-6326(08)60130-2
23. Hwang RY, Chou CP (1997) Corrosion behaviour of weld heat affected zone of aluminium alloy 7075. Sci Technol Weld Join 2:269-274. doi:10.1179/136217197799481131

24. Landolt D, Mischler S, Stemp M (2001) Electrochemical methods in tribocorrosion: a critical appraisal. Electrochim Acta 46:3913-3929. doi:10.1016/S0013-4686(01)00679-X

25. Ehl RG, Ihde AJ (1954) Faraday's electrochemical laws and the determination of equivalent weights. J Chem Educ 31:226-232. doi:10.1021/ed031p226

26. Strong FC (1961) Faraday's laws in one equation. J Chem Educ 38:98. doi:10.1021/ed038p98

27. Pedeferri $P$ (1996) Cathodic protection and cathodic prevention. Constr Build Mater 10:391-402. doi:10.1016/0950-0618(95)00017-8

28. Ashworth V (2010) Principles of cathodic protection. Shreir's Corros 2:2747-2762. doi:10.1016/B978-044452787-5.00152-9

29. Birbilis N, Buchheit RG (2005) Electrochemical characteristics of intermetallic phases in aluminum alloys. J Electrochem Soc 152:B140-B151. doi:10.1149/1.1869984 